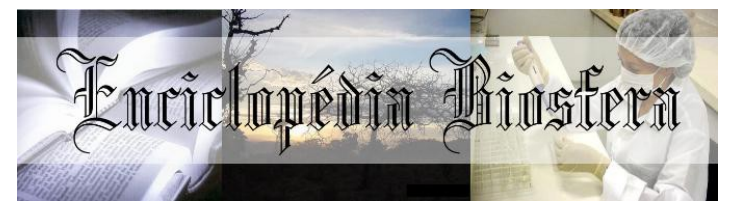

\title{
COMPOSTAGEM E BORRA DE CAFÉ COMO SUBSTRATO NA PRODUÇÃO DE MUDAS DE JILÓ
}

Marina Conceição do Carmo ${ }^{1}$ Jonas Machado Cunico' Poliana Kefler Monteiro da Silva ${ }^{1}$ Caio Bastos de Machado ${ }^{1}$ Geovane Conceição do Carmo ${ }^{2}$

${ }^{1}$ Graduando (a) do curso de Agronomia, Fundação Universidade Federal de

Rondônia - UNIR, Rolim de Moura, Brasil (agrobiologia2@hotmail.com).

${ }^{2}$ Graduando do curso de Arquitetura e Urbanismo, Instituto Federal de

Rondônia - IFRO, Vilhena, Brasil.

Recebido em: 06/04/2018 - Aprovado em: 10/06/2018 - Publicado em: 20/06/2018

DOI: 10.18677/EnciBio_2018A30

\begin{abstract}
RESUMO
O jiló é uma das solanáceas de mais importância no Brasil, sendo cultivado em todas as regiões do país. Uma das etapas de maior relevância na horticultura é a produção de mudas, fator esse que interfere de forma direta no desenvolvimento dessas plantas no campo. Diante disso o objetivo deste trabalho foi avaliar o desenvolvimento inicial de plantas de jiló, utilizando diferentes substratos. As sementes foram semeadas em copos plásticos com as dimensões de $12 \times 22 \mathrm{~cm}$ e volume de $500 \mathrm{~cm}^{3}$, contendo as seguintes misturas $S_{1}=$ Tecnomax puro; $S_{2}=$ solo puro; $S_{3}=$ solo + compostagem $(1: 1 \mathrm{v} / \mathrm{v}) ; \mathrm{S}_{4}=$ solo + borra de café $(10 \%) ; \mathrm{S}_{5}=$ solo + Tecnomax $(1: 1 \mathrm{v} / \mathrm{v}) ; \mathrm{S}_{6}=$ Solo + Tecnomax + borra de café $(10 \%)(1: 1 \mathrm{v} / \mathrm{v}) ; \mathrm{S}_{7}=$ solo + Tecnomax + compostagem (1:1:1 v/v/v); $\mathrm{S}_{8}=$ solo + compostagem + Tecnomax + borra de café $(10 \%)(1: 1: 1 \mathrm{v} / \mathrm{v} / \mathrm{v})$. O delineamento experimental utilizado foi inteiramente casualizado, com 8 tratamentos e 6 repetições. Foi avaliado a germinação e o índice de velocidade de germinação (IVG). Decorridos 34 dias da semeadura avaliaram-se altura de plantas, diâmetro do caule, número de folhas, área foliar, comprimento de raízes, matéria seca de raízes e matéria seca da parte aérea. Para todas as variáveis o tratamento $S_{3}$ a base de compostagem apresentou médias superiores aos demais, seguido pelo tratamento $S_{1}$ (Tecnomax). Conclui-se que substratos com solo + compostagem, podem substituir o substrato comercial, sendo tão eficiente ou melhor na produção de mudas de jiló.
\end{abstract}

PALAVRAS-CHAVE: crescimento; massa seca. Solanum gilo L.;

\section{COMPOSITION AND LEAK OF COFFEE AS A SUBSTRATE IN THE PRODUCTION OF CHILDREN'S JILÓ}

\begin{abstract}
Jiló is one of the most important solanáceas of Brazil, being cultivated in all regions of the country. One of the most important phases of horticulture is the production of seedlings, a factor that directly interferes with the development of these plants in the field. Therefore, the objective of this work was to evaluate the initial development of jiló plants using different substrates. The seeds were seeded in plastic cups with dimensions of $12 \times 22 \mathrm{~cm}$ and volume of $500 \mathrm{~cm}^{3}$, containing the following mixtures $S_{1}$
\end{abstract}


$=$ pure Tecnomax; $S_{2}=$ pure soil; $S_{3}=$ soil + compost $(1: 1 \mathrm{v} / \mathrm{v}) ; S_{4}=$ soil + coffee powder $(10 \%) ; S_{5}=$ solo + Tecnomax $(1: 1 \mathrm{v} / \mathrm{v}) ; S_{6}=$ Soil + Tecnomax + coffee powder $(10 \%)(1: 1 \mathrm{v} / \mathrm{v}) ; S_{7}=$ solo + Tecnomax + compost $(1: 1: 1 \mathrm{v} / \mathrm{v} / \mathrm{v}) ; S_{8}=$ soil + compost + Tecnomax + coffee powder (10\%) (1: 1: $1 \mathrm{v} / \mathrm{v} / \mathrm{v})$. The experimental design was completely randomized, with eight treatments and six replicates. Germination and germination velocity index (IVG) were evaluated. After 34 days of sowing, plant height, stem diameter, number of leaves, leaf area, root length, root dry mass and shoot dry matter were evaluated. For all variables, the treatment $S_{3}(s o i l+$ compost) presented higher averages than the others, followed by treatment $S_{1}$ (Tecnomax). It is concluded that substrates with soil + compost, can substitute the commercial substrate, being as efficient or better in the production of seedlings of jiló..

KEYWORDS: Solanum gilo L.; growth; dry mass.

\section{INTRODUÇÃO}

O jiló (Solanum gilo L.) pertence à família das solanáceas, seus frutos são utilizados na alimentação quando bem desenvolvidos, apresentando sabor característico amargo. Dentre as solanáceas o jiló se configura como uma das culturas de grande importância no cenário hortícola do país, o jiloeiro é cultivado principalmente na região sudeste do Brasil, difundindo-se para outros estados (PINHEIRO et al., 2013; PINHEIRO et al., 2015).

Um das etapas de grande relevância na horticultura é a produção de mudas, a utilização de substratos alternativos é de suma importância. É necessário conhecimento quanto ao desenvolvimento das plantas nesses substratos, uma vez que encontra-se muitos rejeitos de indústria, agricultura e diversas outras matérias primas que tem potencial para esta finalidade (KLEIN, 2015). Uma forma de redução de custos e facilitar a produção do substrato, é fazer a utilização de materiais existentes na propriedade ou região (SEDIYAMA et al., 2014).

A mistura de diferentes substratos pode resultar em melhoras em diversas características das mudas, como altura e tamanho do sistema radicular (FARIA et al., 2016). A utilização de compostos orgânicos pode suprir a necessidade de adubação química ou substrato comercial. Dentre esses substratos alternativos encontra-se a borra de café, produto orgânico abundante, diariamente descartado em lixo doméstico. Sendo um substrato rico em matéria orgânica, potencial para cultivo de mudas (VIDAL et al., 2007; GARCIA et al., 2016). Outro potencial substrato trata-se da compostagem, que é a mistura e decomposição de diferentes resíduos, gerando composto rico em matéria orgânica e diversos nutrientes (OLIVEIRA et al., 2004).

Um substrato adequado deve apresentar ausência de patógenos, disponibilidade adequada de nutrientes essenciais, alta ctc, $\mathrm{pH}$ adequado, textura e estrutura (SILVA et al., 2001). É necessário também que o substrato tenha boa porosidade, para facilitar as trocas gasosas (SANTOS et al., 2015). Porém não há um substrato perfeito que atenda todas as necessidades da espécie a ser cultivada, diante disso torna-se necessário a mistura de compostos (BOENE et al., 2013).

Levando em consideração a grande quantidade de resíduos provenientes do lixo doméstico, da pecuária e da agricultura, o presente trabalho objetivou avaliar o desenvolvimento inicial de mudas de jiló em função de substratos alternativos a base de compostagem e borra de café contendo diferentes fontes de matéria orgânica. 


\section{MATERIAL E MÉTODOS}

O experimento com as mudas de jiló (Solanum gilo L.) foi conduzido no município de Rolim de Moura (RO), na fazenda experimental pertencente à Fundação Universidade Federal de Rondônia - UNIR, localizado no km 15 da Rodovia 479, lado norte (Latitude $11^{\circ} 34^{\prime} 57^{\prime \prime} \mathrm{S}$ e Longitude $61^{\circ} 46^{\prime} 21^{\prime \prime} \mathrm{W}$; altitude de 277 m acima do nível do mar).

$\mathrm{O}$ delineamento experimental adotado foi o inteiramente casualizado com oito tratamentos e seis repetições, totalizando quarenta e oito unidades experimentais. Os tratamentos foram compostos pelo preparo dos substratos baseado na mistura de solo, substrato comercial, com duas fontes de matéria orgânica. Cada tratamento foi composto por uma mistura em partes iguais (volume) dos diferentes substratos, ou seja, nas misturas triplas $33,3 \%$ de cada material, exceto nas misturas que continham a borra de café, nessas foram adicionadas $10 \%$ do volume total do substrato. As fontes de matéria orgânica utilizada foram compostagem e borra de café, misturadas a solo e substrato comercial (Tabela 1).

TABELA 1 Composição dos substratos testados para produção de mudas de jiló.

\section{Composição}

\begin{tabular}{ll}
\hline${ }^{*} S_{1}$ & Tecnomax puro \\
$S_{2}$ & Solo Puro \\
$S_{3}$ & Solo + Compostagem $(1: 1 \mathrm{v} / \mathrm{v})$ \\
$S_{4}$ & Solo + Borra de café $(10 \%)$ \\
$S_{5}$ & Solo + Tecnomax $(1: 1 \mathrm{v} / \mathrm{v})$ \\
$S_{6}$ & Solo + Tecnomax + Borra de café $(10 \%)(1: 1 \mathrm{v} / \mathrm{v})$ \\
$S_{7}$ & Solo + Tecnomax + Compostagem $(1: 1: 1 \mathrm{v} / \mathrm{v} / \mathrm{v})$ \\
$\mathrm{S}_{8}$ & Solo + Compostagem + Tecnomax + Borra de café $(10 \%)(1: 1: 1$ \\
$\mathrm{v} / \mathrm{v} / \mathrm{v})$ & \\
\hline${ }^{*}$ Substratos &
\end{tabular}

*Substratos

O substrato comercial utilizado foi o Tecnomax a base de turfa e vermiculita. A compostagem foi feita 120 dias antes, com os seguintes compostos: bagaço de cana + cama de frango + mucuna + gliricídia + silagem de sorgo forrageiro + braquiária, todos na proporção 1:1. A borra de café foi coletada em cafeterias da cidade. O solo utilizado para as misturas dos substratos é classificado como Latossolo Vermelho-Amarelo distrófico (EMBRAPA, 2013), com as seguintes características: $\mathrm{pH}$ em $\mathrm{H}_{2} \mathrm{O}$ 6,44; M.O $8,36 \mathrm{~g} \mathrm{dm}^{-3} ; \mathrm{P} 1,11 \mathrm{mg} \mathrm{dm}^{-3} ; \mathrm{Na} 0,07 \mathrm{cmol}_{\mathrm{c}}$

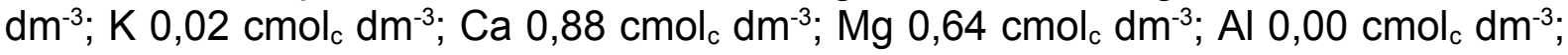
$\mathrm{H}+\mathrm{Al} 3,63 \mathrm{cmol}_{\mathrm{c}} \mathrm{dm}^{-3}$; Arg. 21,0\%; Areia 43,88\%.

As mudas foram produzidas em casa de vegetação no período de fevereiro a março de 2018. O substrato foi comportado em copos plásticos com as dimensões de $12 \times 22 \mathrm{~cm}$ e um volume de $500 \mathrm{~cm}^{3}$. A semeadura ocorreu no dia 15 de fevereiro de 2018, semeando-se em cada recipiente 4 sementes do jiló cultivar 'Jiló comprido grande rio', o desbaste foi realizado 10 DAE (dias após emergência), deixando-se apenas a planta mais vigorosa em cada unidade. As plantas foram irrigadas diariamente, repondo um volume de água suficiente para elevar à umidade do substrato próximo a capacidade de campo.

Foi avaliado germinação (G) e índice de velocidade de germinação (IVG). A Germinação começou no $4^{\circ}$ dia após a semeadura e estendeu-se até o $8^{\circ}$ dia, onde foi feita a contagem diária de sementes germinadas. $O$ índice de velocidade de 
germinação foi calculado pelo somatório do número de sementes germinadas a cada dia, dividido pelo número de dias decorridos entre a semeadura e a germinação, de acordo com a fórmula de Maguire (1962).

$I V G=(G 1 / N 1)+(G 2 / N 2)+(G 3 / N 3)+\ldots+(G n / N n)$, onde:

IVG = índice de velocidade de germinação, G1, G2, G3, .., Gn = número de plântulas computadas na primeira, segunda, terceira e última contagem; e N1, N2, $\mathrm{N} 3, \ldots, \mathrm{Nn}=$ número de dias da semeadura à primeira, segunda, terceira e última contagem.

Aos 34 DAE (21 de março de 2018), as mudas foram coletadas e acondicionadas em embalagens devidamente identificadas de acordo com cada tratamento, sendo posteriormente encaminhadas ao laboratório, onde foram avaliados os seguintes caracteres: a) altura de planta - ALT (cm), b) diâmetro do caule - DC $(\mathrm{mm}), \mathrm{c})$ número de folhas por planta - NFP, d) área foliar - AFP $\left(\mathrm{cm}^{2}\right.$ planta $\left.\left.{ }^{-1}\right), e\right)$ comprimento de raiz $(\mathrm{cm})$, f) massa seca da parte aérea - MSPA (g planta $^{-1}$ ) e massa seca das raízes - MSR (g planta-1 ${ }^{-1}$.

A altura foi mensurada com o auxílio de uma régua graduada, medindo-se a partir do colo ao ápice da muda, o diâmetro do caule foi medido no meio da planta com o auxílio de um paquímetro, o número de folhas por planta foram quantificadas visualmente considerando-se apenas as folhas ativas. Na determinação da área foliar foram medidos: o maior comprimento longitudinal e transversal, segundo a metodologia descrita por Hinnah et al., (2014). O comprimento de raiz foi obtido medindo-se a partir do colo ao ápice da raiz logo após cuidadosa lavagem do sistema radicular. Para determinação da matéria seca da parte aérea e matéria das raízes (g planta ${ }^{-1}$ ), as plantas foram secas em estufa de circulação de ar forçada, a uma temperatura de $65 \mathrm{C}^{\circ}$ até atingir peso constante.

Os dados obtidos foram submetidos à análise de variância pelo teste $f e$ quando significativos aplicados ao teste de Tukey a $5 \%$ de probabilidade para comparação das médias, com o uso do software estatístico SASM - Agri (CANTERI et al., 2001).

\section{RESULTADOS E DICUSSÃO}

Todos os tratamentos deram início a germinação aos 4 DAS (dias após a semeadura). $O$ menor índice de germinação foi encontrado no tratamento $S_{7}$ (solo + substrato + compostagem). Os tratamentos $S_{1}, S_{2}, S_{3}$ e $S_{6}$ tiveram germinação de $100 \%$ (Tabela 2). O melhor IVG foi encontrado no tratamento $S_{1}$ (Tecnomax), seguido do tratamento $S_{3}$ (solo + compostagem), o menor valor encontrado foi no tratamento com solo + borra de café $(10 \%)$ com IVG de 1,12, como pode ser observado na tabela 2 .

TABELA 2 - Resultado da análise de Germinação (G\%) e índice de velocidade de germinação (IVG)

\begin{tabular}{|c|c|c|c|}
\hline Tratamento & G\% & IVG & \\
\hline S1 & 100 & 2,94 & \\
\hline S2 & 100 & 1,19 & \\
\hline S3 & 100 & 2,61 & \\
\hline S4 & 91.1 & 1,12 & \\
\hline S5 & 89.6 & 1,15 & \\
\hline S6 & 100 & 2,04 & \\
\hline ESHAEICLOPÉDIA B & OSFERA, Centro Cient & fico Conhecer - Goiânia, v. $2,2{ }^{2}{ }^{2} 27 ;$ p. 73 & 2018 \\
\hline S8 & 90 & 1,37 & \\
\hline
\end{tabular}


Foi verificada diferença significativa na variável altura de plantas (ALT) nas mudas de jiloeiro, uma vez que os tratamentos $S_{3}$ e $S_{1}$ apresentaram as melhores médias (solo + compostagem e Tecnomax puro), 5,5 e 4,6 cm respectivamente, onde 0 tratamento $S_{4}$ apresentou a menor média $(1,37 \mathrm{~cm})$ não diferindo dos tratamentos $S_{8}, S_{7}, S_{6}, S_{5}$ e $S_{2}$ (Tabela 3 ). O substrato de solo + compostagem apresentou-se tão eficiente quanto ao substrato comercial, e acima da média dos outros compostos testados nesse experimento, isso infere a capacidade de produção do substrato dentro da propriedade, com compostos simples facilmente produzidos. Ferraz et al., (2005) avaliando as características físicas e químicas de substratos comerciais, concluiu que o substrato comercial germina a base de turfa + vermiculita, apresentam propriedades físicas próximas ao indicado para plantas, e apresentaram altos teores de nutrientes e saturação por bases, o que propicia condições adequadas para o desenvolvimento das plantas.

TABELA 3 - altura da planta - ALT (cm); Diâmetro do caule - DC (mm); Número de folhas por planta - NFP; Área foliar - AF $\left(\mathrm{cm}^{2}\right.$ planta $\left.{ }^{-1}\right)$; comprimento de raiz - CR $(\mathrm{cm})$; matéria seca parte aérea - MSPA (g.planta- $\left.{ }^{-1}\right)$; matéria seca da raiz - MSR (g.planta-1 $)$.

\begin{tabular}{clllllll}
\hline Substrato & ALT & DC & NFP & AF & CR & MSPA & MSR \\
\hline S1 & $4,66 \mathrm{ab}$ & $1,3 \mathrm{~b}$ & $5,8 \mathrm{ab}$ & $7,65 \mathrm{~b}$ & $25,7 \mathrm{a}$ & $0,046 \mathrm{~b}$ & $0,0716 \mathrm{bc}$ \\
S2 & $1,8 \mathrm{c}$ & $0,78 \mathrm{c}$ & $2,8 \mathrm{de}$ & $0,63 \mathrm{c}$ & $14,2 \mathrm{~b}$ & $0,01 \mathrm{c}$ & $0,075 \mathrm{~b}$ \\
$\mathrm{~S} 3$ & $5,5 \mathrm{a}$ & $2,0 \mathrm{a}$ & $6,2 \mathrm{a}$ & $16,92 \mathrm{a}$ & $24,56 \mathrm{a}$ & $0,164 \mathrm{a}$ & $0,184 \mathrm{a}$ \\
S4 & $1,37 \mathrm{c}$ & $0,25 \mathrm{~d}$ & $2,0 \mathrm{e}$ & $0,12 \mathrm{c}$ & $1,47 \mathrm{~d}$ & $0,0017 \mathrm{c}$ & $0,00075 \mathrm{~d}$ \\
S5 & $2,38 \mathrm{c}$ & $0,84 \mathrm{c}$ & $4,0 \mathrm{~cd}$ & $1,79 \mathrm{c}$ & $9,84 \mathrm{bc}$ & $0,00841 \mathrm{c}$ & $0,00962 \mathrm{~d}$ \\
S6 & $2,76 \mathrm{bc}$ & $0,4 \mathrm{~d}$ & $2,0 \mathrm{e}$ & $0,21 \mathrm{c}$ & $4,84 \mathrm{~cd}$ & $0,00238 \mathrm{c}$ & $0,00304 \mathrm{~d}$ \\
S7 & $1,8 \mathrm{c}$ & $0,9 \mathrm{c}$ & $4,33 \mathrm{bc}$ & $2,36 \mathrm{c}$ & $9,63 \mathrm{bc}$ & $0,00772 \mathrm{c}$ & $0,02303 \mathrm{~cd}$ \\
S8 & $1,77 \mathrm{c}$ & $0,37 \mathrm{~d}$ & $2,5 \mathrm{e}$ & $0,38 \mathrm{c}$ & $4,25 \mathrm{~cd}$ & $0,0027 \mathrm{c}$ & $0,00305 \mathrm{~d}$ \\
\hline CV\% & $42,90 \%$ & $19,19 \%$ & $21,79 \%$ & $33,72 \%$ & $26,66 \%$ & $51,42 \%$ & $58,99 \%$ \\
\hline
\end{tabular}

*Letras minúsculas iguais na coluna não diferem pelo teste de Tukey ao nível de $5 \%$ de probabilidade.

Para a variável diâmetro de caule (Tabela 3 ) verificaram-se resultados significativos, sendo o tratamento solo + compostagem superior que os demais tratamentos seguido pelo Tecnomax, tal resultado está possivelmente ligado com o maior teor de matéria orgânica, o que proporciona melhores condições físicas e químicas, favorecendo o desenvolvimento das plantas. Esse resultado se relaciona diretamente com o número de folhas (NFP) onde os tratamentos $S_{3}$ e $S_{1}$ apresentaram-se superiores aos outros, tendo a média por plantas de 6,2 e 5,8 folhas, respectivamente.

As folhas são órgãos essenciais, maior quantidade de folhas aumenta a taxa fotossintética, o que reflete diretamente no crescimento da planta. Esses resultados estão acima da média dos que encontrados por Steffen et al., (2010) avaliando mudas de tomates em substrato a base de casca de arroz e esterco bovino, não verificando diferença nessa variável, concluiu que o número médio de folhas por planta varia de 4 a 5 . Proporcional ao número de folhas, a área foliar mostrou-se maior no tratamento $S_{3}\left(16,92 \mathrm{~cm}^{2}\right)$ seguida pelo $S_{1}\left(7,65 \mathrm{~cm}^{2}\right)$, esses resultados confirmam as aferições anteriores, este atributo é indicativo de fitomassa e produtividade. A área foliar (AF) é de extrema importância para moldar o 
crescimento e desenvolvimento das plantas, o que implicará posteriormente na produtividade da cultura em campo (REIS et al., 2013).

Para a variável comprimento de raízes (CR) os substratos $S_{3}$ e $S_{1}$ não diferiram significativamente, apresentado comprimento médio de $25 \mathrm{~cm}$, sendo superiores aos demais tratamentos. O menor comprimento de raiz foi encontrado no tratamento $\mathrm{S}_{4}$ composto por solo + borra de café $(10 \%)$ com média de $1,47 \mathrm{~cm}$, sendo inclusive menor que o tratamento $S_{2}$ com solo puro atingindo média de 14,2 cm (Tabela 3). Cruz (2015) estudando o desenvolvimento de cenoura, espinafre e alface, observou que a germinação, crescimento e produtividade destas plantas, foram reduzidas pela presença de borra de café expresso.

A variável matéria seca da parte aérea (MSPA) e matéria seca das raízes (MSR) foi proporcional aos demais resultados encontrados, o tratamento com solo + compostagem $\left(\mathrm{S}_{3}\right)$ apresentou maior quantidade de matéria seca tanto nas raízes como na parte aérea, isso se confirma devido ao fato desse tratamento ter apresentado o maior número e tamanho de folhas, altura de planta, diâmetro de caule e comprimento de raízes, os menores valores de matéria seca se associam aos menores resultados encontrados nessas variáveis, pode-se verificar qual substrato forneceu mais nutrientes através da matéria seca das mudas. Medeiros et al., (2013) avaliando substrato composto orgânico e comercial Plantmax® na produção de mudas de tomate, verificaram que o substrato orgânico proporcionou maior massa seca, tanto do sistema radicular como da parte aérea, isso foi atribuído ao melhor teor de nutrientes e maior retenção de umidade.

Também pode ser observado na tabela 3, que os tratamentos que receberam a adição de borra de café, apresentaram resultados tão baixos ou menores que o tratamento com solo puro $\mathrm{S}_{2}$. Esses resultados corroboram com o de Wangen et al., (2015) onde testando níveis de borra de café adicionados ao substrato na produção de mudas de alface, constataram que níveis mais altos que $10 \%$ de borra afeta negativamente o desenvolvimento das plantas, decaindo de forma linear. Kiehl (2010) justifica que a borra de café não deve ser utilizada de forma direta como fertilizante orgânico, havendo a necessidade de compostagem para evitar danos nas plantas.

Os melhores resultados em todas as variáveis foram encontrados no tratamento com solo + compostagem $\left(\mathrm{S}_{3}\right)$ (Tabela 3$)$ o composto orgânico atua como condicionador melhorando as propriedades físico-químicas e biológicas do solo, fornecendo nutrientes, favorecendo um rápido enraizamento, o que aumenta a resistência das plantas e proporciona condições para seu desenvolvimento (SOUZA; ALCÂNTARA, 2008). Freitas et al., (2011) testando em mudas de abacaxi, compostagem de bagaço de cana-de-açúcar + torta de filtro e mistura de substrato comercial Plantamax ${ }^{\circledR}$ hortaliças + areia + solo, não observaram diferenças significativas no comprimento de plantas, diâmetro de colo, número de folhas e matéria seca da parte aérea, o que indica que misturas provenientes de compostagem fornecem os mesmo subsídios que substratos comerciais para 0 desenvolvimento de mudas.

Santos et al., (2013) avaliando a mistura de substrato com composto orgânico de lixo urbano na produção de mudas de Eucalyptus urophylla, observaram resultado contrário ao encontrado nesse trabalho, onde o tratamento testemunha com $0 \%$ de composto orgânico apresentou os melhores resultados, confirmando que é de extrema importância a origem da matéria orgânica. Ferraz et al., (2014) estudando o desenvolvimento de mudas de bertalha em diferentes substratos, constataram que o substrato com composto orgânico + cama-de-aviário + casca de 
arroz carbonizada + carvão vegetal, apresenta resultados semelhantes ao substrato comercial Plantimax em altura de plantas, massa seca de raízes, massa seca da parte aérea e massa seca total, podendo ser produto substituto deste. Reis et al., (2014) ressaltam que esses parâmetros avaliados são importantes indicativos de qualidade, uma vez que o crescimento é resultado da quantidade de nutrientes absorvida do substrato.

\section{CONCLUSÃO}

O tratamento solo + compostagem $\left(\mathrm{S}_{3}\right)$ apresentou-se melhor que os demais tratamentos em todas as variáveis estudadas.

O melhor IVG foi encontrado no tratamento $S_{1}$ (Tecnomax) seguido pelo tratamento $\mathrm{S}_{3}$ (solo + compostagem).

O substrato com solo + compostagem, pode substituir o substrato comercial.

\section{REFERÊNCIAS}

BOENE, M. A. C. H.; NOGUEIRA, C. A.; SOUSA, J. N.; KRATZ, D.; SOUZA, D. V. P. Efeitos de diferentes substratos na produção de mudas de Sebastiania commersoniana. Floresta, v. 43, n. 3, p. 407 - 420, 2013. Disponível em: http://dx.doi.org/10.5380/rf.v43i3.25789.

CANTERI, M. G.; ALTHAUS, R. A.; VIRGENS FILHO, J. S.; GIGLIOTI, E. A.; GODOY, C. V. SASM - Agri : Sistema para análise e separação de médias em Experimentos agrícolas pelos métodos Scoft - Knott, Tukey e Duncan. Revista Brasileira de Agrocomputação, v.1, n.2, p.18-24. 2001. Disponível em: http://www.agrocomputacao.deinfo.uepg.br/dezembro_2001/arquivos/rbac_artigo_03 .pdf > Acesso em: 19 mar. 2018.

CRUZ, S. Espresso coffee residues as a nitrogen amendment for small-scale vegetable production. Journal of the Science of Food and Agriculture, v. 95, s/n, p. 3059-3066, 2015. Disponível em: https://doi.org/10.1002/jsfa.7325.

Empresa Brasileira de Pesquisa Agropecuária - Embrapa. Sistema brasileiro de classificação de solos. 3. ed. Brasília: Embrapa; 2013.

FARIA, J. C. T.; CALDEIRA, M. V. W.; DERLAMELINA, W. M.; ROCHA, R. L. F. Substratos alternativos na produção de mudas de Mimosa setosa Benth. Ciência Florestal, v. 26, n. 4, p. 1075-1086, 2016. Disponível em: http://dx.doi.org/10.5902/1980509824996.

FERRAZ, A. P.; MENDES, R.; NETO, A. E. S. de.; FERREIRA, F. L. R. Produção de mudas orgânicas de bertalha em diferentes substratos. Enciclopédia Biosfera, v.10, n.18, p. 2442, 2014. Disponível em: < http://www.conhecer.org.br/enciclop/2014a/AGRARIAS/producao\%20de \%20mudas\%20organicas.pdf> Acesso em: 13 mar. 2018.

FERRAZ, M. V.; CENTURION, J. F.; BEUTLER, A. N. Caracterização física e química de alguns substratos comerciais. Acta Scientiarum Agronomy, v. 27, n. 2, p. 209-214, 2005. Disponível em: http://dx.doi.org/10.4025/actasciagron.v27i2.1483. 
FREITAS, J. de. S.; CARVALHO, C. J. A. de.; BERILLI, S. da. S.; SANTOS, P. C. dos.; MARINHO, S. C. Substratos e Osmocote ${ }^{\circledR}$ na nutrição e desenvolvimento de mudas micropropagadas de abacaxizeiro cv. Vitória. Revista Brasileira de Fruticultura, Volume Especial, E. 672-679, Outubro 2011. Disponível em: http://dx.doi.org/10.1590/S0100-29452011000500094.

GARCIA, R. V.; COSTA, A. C.; DELPRETE, S. I.; SILVA, M. G.; LIMA, W. L. Efeito da Borra de Café na formação de mudas de pepino (Cucumis sativus L.). Cadernos de Agroecologia, v. 11, n. 2, 2016. ISSN 2236-7934. Disponível em: <http://revistas.aba-agroecologia.org.br/index.php/cad/article/view/21565>. Acesso em: 20 mar. 2018.

HINNAH, F. D.; HELDWEIN, A. B.; MALDANER, I. C.; LOOSE, L. H.; LUCAS, D. D. P.; BORTOLUZZI, M. P. Estimativa de área foliar da berinjela em função das dimensões foliares. Bragantia, v. 73, n. 3, p.213-218, 2014. Disponível em: http://dx.doi.org/10.1590/1678-4499.0083.

KIEHL, EJ. Novos fertilizantes orgânicos. Piracicaba: $1^{a}$ edição do autor. 248 p, 2010.

KLEIN, C. Utilização de substratos alternativos para a produção de mudas. Revista Brasileira de Energias Renováveis, v.4, s/n, p. 43-63, 2015. Disponível em: http://dx.doi.org/10.5380/rber.v4i3.40742.

MAGUIRE, J. D. Speed of germination aid in selection and evaluation for seedling emergence and vigor. Crop Science, v.2, n.1, p.176-177. 1962. Disponível em: http://dx.doi.org/10.2135/cropsci1962.0011183X000200020033x.

MEDEIROS, D.C.; AZEVEDO, C.M.S.B.; MARQUES, L.F.; SOUSA, R.A.; OLIVEIRA, C.J. Qualidade de mudas de tomate em função do substrato e irrigação com efluente de pisicultura. Revista Brasileira de Agroecologia, v. 8, n. 2, 2013. ISSN 19809735. Disponível em: <http://revistas.abaagroecologia.org.br/index.php/rbagroecologia/article/view/10389>. Acesso em: 23 mar. 2018.

OLIVEIRA, F. N. S.; MOREIRA FILHO, H. J.; CAJAZEIRA, J. P. Uso da compostagem em sistemas agrícolas orgânicos. Embrapa Agroindústria Tropical, 17p. 2004. (Documentos 89).

PINHEIRO, J. B.; PEREIRA, R. B.; CARVALHO, A. D. F. de.; AGUIAR, F. M. Ocorrência e manejo de nematoides na cultura do jiló e berinjela. Embrapa, 2013. (Circular técnica, 125).

PINHEIRO, J. B.; PEREIRA, R. B.; FREITAS, R. A. de.; MELO, R. A. de. C. e. A cultura do jiló. Embrapa, 70p. 2015. (Coleção Plantar, 75). 
REIS, L. S.; AZEVEDO, C. A. V. de.; ALBURQUERQUE, A. W.; SILVA JUNIOR, F. J. Índice de área foliar e produtividade do tomate sob condições de ambiente protegido. Revista Brasileira de Engenharia Agrícola e Ambiental. v.17, n.4, p.386-391, 2013. Disponível em: http://dx.doi.org/10.1590/S141543662013000400005.

REIS, R. M. J.; RODRIGUES, F. J.; REIS, A. de. M. Produção de mudas de maracujazeiro amarelo com diferentes substratos. Enciclopédia Biosfera, v.10, n.18, p. 2423, 2014. Disponível em: < http://www.conhecer.org.br/enciclop/2014a/AGRARIAS/producao\%20de \%20mudas.pdf> Acesso em: 09 mar. 2018.

SANTOS, C. D. da.; FERREIRA, F. L. R.; NETO, A. E. S. de.; QUEIROZ, F. E. de.; MEDEIROS, S. R. da. Produção de mudas de tomateiro em substratos alternativos. Enciclopédia Biosfera, v.11 n.21, p. 1530, 2015. Disponível em: < http://www.conhecer.org.br/enciclop/2015b/agrarias/producao\%20de\%20mudas \%20de\%20tomateiro.pdf> Acesso em: 21 mar. 2018.

SANTOS, V. E. F.; ARAÚJO, M. J.; ANDRADE, C. W.; COSTA, C. C. da.; SILVA, G. A. da. Formação de mudas de Eucalyptus urophylla s.t. blake com utilização de resíduo sólido orgânico urbano. Enciclopédia Biosfera, v.9, N.16, p. 1203, 2013. Disponível em: < http://www.conhecer.org.br/enciclop/2015b/agrarias/producao \%20de\%20mudas\%20de\%20tomateiro.pdf> Acesso em: 11 mar. 2018.

SEDIYAMA, N. A. M.; SANTOS, C. I. dos.; LIMA, C. P. de. Cultivo de hortaliças no sistema orgânico. Revista Ceres, v. 61, Suplemento, p. 829-837, 2014. Disponível em: http://dx.doi.org/10.1590/0034-737x201461000008.

SILVA, P. R. da.; PEIXOTO, R. J.; JUNQUEIRA, V. T. N. Influência de diversos substratos no desenvolvimento de mudas de maracujazeiro azedo (Passiflora edulis sims f. flavicarpa deg). Revista Brasileira de Fruticultura, v.23 n.2, 2001. Disponível em: http://dx.doi.org/10.1590/S0100-29452001000200036.

SOUZA, B. R. de.; ALCÂNTARA, A. D. de. Adubação no sistema orgânico de produção de hortaliças. EMBRAPA, 2008, (Circular técnica, 65).

STEFFEN, K. P. G.; ANTONIOLLI, I. Z.; STEFFEN, B. R.; MACHADO, G. R. Casca de arroz e esterco bovino como substratos para a multiplicação de minhocas e produção de mudas de tomate e alface. Acta Zoológica Mexicana, v. 26, n.s, p. 333-343, 2010. Disponível em: < http://www.scielo.org.mx/scielo.php? script=sci_arttext\&pid=S0065-17372010000500025> Acesso em: 07 mar. 2018.

VIDAL, M. B.; VITTI, M. R.; MORSELLI, T. B. G. A. CARACTERIZAÇÃO QUÍMICA DE VERMICOMPOSTOS DE DIFERENTES SUBSTRATOS ORGÂNICOS. Cadernos de Agroecologia, v. 2, n. 1, 2007. ISSN 2236-7934. Disponível em: <http://revistas.abaagroecologia.org.br/index.php/cad/article/view/2175>. Acesso em: 13 mar. 2018.

WANGEN, B. R. D.; CARDOSO, R. T. M.; FREITAS, O. R.; FERNANDES, F. E.; DUARTE, M. G.; PINTO, J. F. de. A. Borra de café na produção de alface, Lactuca 
sativa L. Enciclopédia Biosfera, v.11 n.22, p. 518, 2015. Disponível em: http://dx.doi.org/10.18677/Enciclopedia_Biosfera_2015_105. 